\title{
THE PROFILE OF PATIENTS PRESENTED AT NEPHROLOGY OPD WITH OBSTRUCTIVE NEPHROPATHY; SINGLE CENTRE EXPERIENCE
}

\author{
KAZI SHAHNOORALAM ${ }^{1}$, MD. SHAWKAT ALAM ${ }^{1}$, TOFAELAHAMMOD ${ }^{2}$, MDMAHMUDUL HASAN ${ }^{3}$, \\ TASLIMA AFROSE ${ }^{4}$, DILIP KUMAR DEBNATH ${ }^{1}$, MOHAMMOD BABRUL ALAM ${ }^{1}$
}

\begin{abstract}
:
Introduction: Obstructive Uropathy which refers to the structural and functional change impeding the normal urine flow is one of the common cause of renal failure. It has diverse effect on normal renal function as well as there is also diversity on its etiology and outcome .

Material \& methods: Total 108 patients who came to Nephrology OPD with various degree of renal dysfunction resulting from Obstruction of Urinary tract was included in the study.

Result : Among the patients $65 \%$ were male and their mean age was $51 \pm 13.5$ years . Common clinical features were loin pain (41\%); vomiting (30\%) ; edema (26\%) ; Oligourea (46\%) \& LUTS (19\%). Common etiologies of Obstruction was BEP (28.7\%);Urolithiasis(24\%); Cervical malignancies(11\%); Congenital abnormalities (13\%) \& stricture urethra(12\%). About $37 \%$ patients had to under go RRT.

Conclusion : Specific strategies to target improvements in early diagnosis renal recovery and patients survival are needed in this patient group.
\end{abstract}

Bangladesh J. Urol. 2019; 22(2): 132-135

\section{Introduction}

Obstructive uropathy is refers to the structural and functional change in the urinary tract that impede the normal urine flow. Obstructive uropathy is one of the most common urological emergency. It may be acute or chronic; complete or incomplete; unilateral or bilateral and can lead to rapid worsening of renal function and irreversible kidney damage if urinary damage is not rapidly corrected[1,2]. When urine flow is blocked at any point in the urinary tract, it leads to accumulation of urine above the site of the obstruction. There is development of back pressure and urine moves up the urinary tract as far as the renal pelvis it leads to

1. National Institute of Kidney Diseases and Urology.

2. Shaheed Syed Nazrul Islam Medical College, Kishorgonj .

3. Seikh Hasina Institute Of Burn And Plastic Surgery, Dhak

4. Dhaka Medical College, Dhaka

Correspondences: Kazi ShahnoorAlam, National Institute of Kidney Diseases and Urology., Dhaka

Received: 05 February 2019

Accepted: 10 May 2019 dilatation of the ureter, renal pelvis and calyces (according to the site of obstruction ).

Obstructive uropathy has diverse effect on renal function. There will be marked reduction in renal blood flow and glomerular filtration rate along with significant changes in renal tubular function[3]. Partial chronic obstruction of the urinary tract can cause progressive atrophy and destruction of the nephrons leading to chronic renal insufficiency. Unilateral complete obstruction of urine flow if tolerated more for about one week following which a permanent damage likely to occur. Complete obstruction continuing for more than three weeks recovery of renal function is unlikely to occur.

The etiologies of obstructive uropathy are diverse. Largely determined by the age of the patient. In children the main etiologies are uretero-pelvic junction obstruction and congenital urethral valves. In young 


\section{2(2) 2019}

The Profile of Patients Presented at Nephrölogy OPD With Obstructive Nephropathy; Single Centre Experience

adult , calculi are the common causes[4]. On the other hand benign prostetic enlargement and malignancy are the common in case of older patients .

The clinical features of obstructive uropathy includes loin pain , lower urinary tract symptoms, fever, mass effect with uremic features. But there may be nonspecific features $[4,5,6]$.

Regardless patients age, appropriate diagnosis and prompt surgical and interventional drainage are necessary to avoid irreversible renal damage[7], It is often reversible and degree of renal recovery depends primarily on the extent and duration of the obstruction together with the presence and absence of other co morbidity[8].

\section{Materials and method}

This is a cross sectional study carried out in National Institute of Kidney Diseases and Urology ,Sher-EBangla Nagar; Dhaka; Bangladesh; a specialized hospital for kidney patients in the country. Study period was from Jan' 2018 to June '2018. During the period total 108 patients were included to the study who came to nephrology out patient department with various degree of renal failure resulting from obstruction in urinary tract.

\section{Results:}

Sixty five percents of total patients(108) were men (Tablell). Mean age of them was $51 \pm 13.5$ years (Table-II). Seventy percents were from rural community (Table III). About $36 \%$ were smokers where $31 \%$ were taking beetle leaf .Main co morbidities are hypertension $(60 \%)$ and diabetes (19\%) (Table V). Main clinical features wereloin pain (41\%); vomiting (30\%); edema (26\%); Oligourea (46\%) LUTS (19\%); anuria(6\%); and microscopic hematuria (7\%) (Table-VI). Mean s. creatinine was $8.34 \pm 3.69 \mathrm{mg} / \mathrm{dl}$ and emergency RRT was given to about $37 \%$ patients. Main etiologies of obstruction were BEP (28.7\%); Urolithiasis(24\%); Cervical malignancies (11\%); Congenital abnormalities (13\%); stricture urethra (12\%); Other malignancies (prostate, bladder) (5.6\%); Neurogenic bladder(5.6\%) (Table-V) etc. Ultrasonographic findings shows (according to the SFU grading system ) $3.7 \%$ belongs to grade 0 where $18.5 ; 14.8 ; 17.6$ and $36 \%$ belongs to grade $1 ; 2 ; 3 \& 4$ accordingly.
Table-I

Distribution of the patients according to age $(n=108)$

\begin{tabular}{lcc}
\hline Age (years) & Frequency $(\mathrm{n})$ & Percentage $(\%)$ \\
\hline$\leq 30$ & 11 & 10.2 \\
$31-40$ & 12 & 11.1 \\
$41-50$ & 24 & 22.2 \\
$51-60$ & 36 & 33.3 \\
$>60$ & 25 & 23.1 \\
\hline Total & 108 & 100.0 \\
Mean $\pm S D$ & $51.8 \pm 13.5$ & \\
\hline
\end{tabular}

Table II

Distribution of the patients according to gender $(n=108)$

\begin{tabular}{lcc}
\hline Gender & Frequency $(\mathrm{n})$ & Percentage $(\%)$ \\
\hline Male & 70 & 64.8 \\
Female & 38 & 35.2 \\
\hline Total & 108 & 100.0 \\
\hline
\end{tabular}

Table III

Distribution of the patients according to residence $(n=108)$

\begin{tabular}{lcc}
\hline Residence & Frequency $(\mathrm{n})$ & Percentage (\%) \\
\hline Urban & 16 & 14.8 \\
Semi urban & 22 & 20.4 \\
Rural & 70 & 64.8 \\
Total & 108 & 100.0 \\
\hline
\end{tabular}

Table-V

Distribution of the patients according to primary disease $(n=108)$

\begin{tabular}{lcc}
\hline Primary disease & $\begin{array}{c}\text { Frequency } \\
(\mathrm{n})\end{array}$ & $\begin{array}{c}\text { Percentage } \\
(\%)\end{array}$ \\
\hline Congenital malformations & 14 & 13.0 \\
Stricture urethra & 13 & 12.0 \\
Urolithiasis & 26 & 24.1 \\
Benign prostatic enlargement & 31 & 28.7 \\
Cervical malignancy & 12 & 11.1 \\
Neurogenic bladder & 6 & 5.6 \\
Others ( prostetic, & 6 & 5.6 \\
bladder malignancy) & & \\
\hline
\end{tabular}


Table-V

Distribution of the patients according to co-morbid disease $(n=108)$

\begin{tabular}{lcc}
\hline Co-morbid disease & $\begin{array}{c}\text { Frequency } \\
(\mathrm{n})\end{array}$ & $\begin{array}{c}\text { Percentage } \\
(\%)\end{array}$ \\
\hline HTN & 65 & 60.2 \\
CKD & 28 & 25.9 \\
IHD & 4 & 3.7 \\
DM & 21 & 19.4 \\
Hyperthyroidism & 4 & 3.7 \\
COPD & 2 & 1.9 \\
ADPDK & 5 & 4.6 \\
\hline
\end{tabular}

Table VI

Distribution of the patients according to presenting symptom $(n=108)$

\begin{tabular}{lcc}
\hline Presenting symptom & $\begin{array}{c}\text { Frequency } \\
(\mathrm{n})\end{array}$ & $\begin{array}{c}\text { Percentage } \\
(\%)\end{array}$ \\
\hline Loin pain & 44 & 40.7 \\
Vomiting & 32 & 29.6 \\
Fever & 40 & 37.0 \\
Swelling of legs & 28 & 25.9 \\
Oliguanuria & 50 & 46.3 \\
Rsp. distress & 13 & 12.0 \\
LUTS & 20 & 18.5 \\
Acute Urinary retention & 7 & 6.5 \\
Haematuria & 6 & 5.6 \\
Abdominal pain & 2 & 1.9 \\
Lump in abdomen & 1 & 0.9 \\
\hline
\end{tabular}

${ }^{*}$ Multiple responses

\section{Discussion}

This small study was carried out in National Institute of Kidney Diseases and Urology (NIKDU) Sher-E-Bangla Nagar; Dhaka to see the clinical profile of obstructiveuropathy came to the nephrology Outpatient department having significant renal dysfunction. Patients presented with various symptoms (uremic, overload and anuria) and $37 \%$ were underwent emergency renal replacement therapy. Hypertension and DM were the main associated co-morbidities. Mean s.creatinine of this study was $8.34 \pm 3.69 \mathrm{mg} / \mathrm{dl}$ which is higher then the study carried out in Indiaand Cameroon $[9,10]$. It may be due to Our patients were mainly referred from Urology OPD and significant renal function impairment was the cause of referral.

Urinary tract obstruction is a common clinical problem. It may be acute or chronic; partial or complete; unilateral or bilateral ; can occur any site of urinary tract and lead to rapid deterioration of renal function and irreversible kidney damage if not treated in time[4]. In our study we included patients having significant renal dysfunction and $37 \%$ patients had to underwent RRT which was similar to the study carried out in Cameroon[10].

Clinical features of obstructive uropathy are often nonspecific, depending on the time interval over which the obstruction occurs, the lateralization and the severity of obstruction. Although a decrease in urinary output is frequently observed, normal and increased urine output does not exclude partial obstruction . In this study $6 \%$ patients presented as anuria and $46 \%$ oliguria. The sum total is consistent with other studies[6,10,11]. BPH is the most common cause of obstruction in this patient group where urolithiasis is the second most common. Our result are similar or closer to the studies[6,10,11]. Malignancies are about $16 \%$ causes of obstruction in our series. It is lower than the study carried in Cameroon[9] where it is about 32\% ; but higher than the study done in Soudan[5] where it is about $8 \%$. This different is may be due to the referral system varied in country to country.

About $3.7 \%$ patients ultara-sonography showed there was no hydronephrotic changes. In cases of acute obstruction there may be no hydronephrotic change . Other patients USG shows mild to severe obstructive feature in either or both kidneys.

Limitations: There are some limitations in this study. As all the patients attended in Nephrology outpatients department could not be treated in the same hospital we could not followed up them and outcome could not me included properly. It was in a single centre so findings may not be generalized. However the study is first to describe the profile of patients with obstructive uropathy in our settings, in a specialized hospital . It therefore provides background data that will contribute to raise awareness and enhance research in this field.

\section{Conclusion:}

Patients with obstructive uropathy in this study presented with significant renal function impairment. BEP and stone diseases are most common causes of 
The Profile of Patients Presented at Nephrology OPD With Obstructive Nephropathy; Single Centre Experience

obstruction . Number of patients were has to given renal replacement therapy but proper outcome can not be estimated. Specific strategies to target improvements in early diagnosis renal recovery and patients survival are needed in this patient group .

\section{References:}

1. Ishidoya $S$, Kaneto H, Fukuzaki A, Takeda A, Ogata Y,Nakagawa H, Orikasa S, Arai Y. Pathophysiology and clinical implication of obstructive nephropathy. NihonHinyokika GakkaiZasshi.2003; 94:645-55.

2. Tang X, Lieske JC. Acute and chronic kidney injury in nephrolithiasis. CurrOpinNephrol Hypertens. 2014; 23:385-90

3. FS W. Effects of Urinary tract obstruction on glomerular filtration rate and renal blood flow .SeminNephrol. 1982;2:11

4. Ibrahim AG, Aliyu S, Ali N. Bilateral pelvi-ureteric junction obstruction: our experience in a developing country. Niger J Clin Pract.2014; 17:267-69.

5. El Imam M, Omran M, Nugud F, Elsabiq M, Saad K, Taha O. Obstructive Uropathy in Sudanese Patients. Saudi J Kidney Dis Transplant.2006 Sep;17(3):415-9.
6. $\quad$ Wang SJ, Mu XN, Zhang LY, Liu QY, Jin XB. The incidence and clinical features of acute kidney injury secondary to ureteral calculi.Urol Res. 2012 Aug;40(4):345-8.

7. Chevalier RL, Klahr S. Therapeutic approaches in obstructive uropathy.SeminNephrol.1998; 18:652-58.

8. Lucarelli G, Ditonno P, Bettocchi C, Grandaliano G, Gesualdo L, Selvaggi FP, Battaglia M. Delayed relief of ureteral obstruction is implicated in the long-term development of renal damage and arterial hypertension in patients with unilateral ureteral injury.J Urol.2013; 189:960-65.

9. Pal DK; Sasmal S. Clinical profile and Treatment Outcome of Obstructive Uropathy In a Tertiary Care Centre . ARC Journal of Urology . 2017,pp5-10.

10. Halle MP; Toukep LN; Nzuobontane SE; Ebana F ; Ekana GH ; Priso EB. The profile of patients with obstructive uropathy in Cameroon ; case of Douala Hospital ; Pan Afr Med J 2016;23:67

11. Organ M, Norman RW. Acute reversible kidney injury secondary to bilateral ureteric obstruction.CanUrolAssoc J. 2011 Dec; 5(6): 392-6. 